\title{
SŁAWOMIR TRUSZ
}

Uniwersytet Pedagogiczny im. Komisji Edukacji Narodowej

w Krakowie

\section{O ZNACZENIU BADAŃ ILOŚCIOWO-JAKOŚCIOWYCH W EDUKACJI. PRÓBA ŁĄCZENIA WODY Z OGNIEM...}

\begin{abstract}
Trusz Sławomir, O znaczeniu badań ilościowo-jakościowych w edukacji ${ }^{1}$. Próba łączenia wody z ogniem... [The Meaning of Mixed Quantitative and Qualitative Research in Education. An Attempt to Combine Fire and Water]. Studia Edukacyjne nr 44, 2017, Poznań 2017, pp. 93-104. Adam Mickiewicz University Press. ISSN 1233-6688. DOI: 10.14746/se.2017.44.6

Social research, including educational studies, could be conducted in accordance with ontological and epistemological assumptions of quantitative vs. qualitative research orientations. When such a distinction is present, the same phenomena are analyzed and presented in a significantly different and often mutually excluding way. Is such an approach justified? It seems it is not. Based on the precedence of a research subject over the method, it could be said that a more comprehensive picture of the phenomena analyzed emerges when researchers make use of methods accepted in both quantitative and qualitative research orientations. The article presents theoretical assumptions and interesting practical solutions of a mixed approach (a mixed methodology) in social research. On the one hand, solutions and methods recommended for the quantitative research can be useful for studies conducted in accordance with the assumptions of qualitative orientation, and on the other hand, solutions and methods recommended for the qualitative research may be useful for the studies conducted in accordance with the assumptions of quantitative orientation. Both approaches have been illustrated by particular examples of research practices.
\end{abstract}

Key words: social research, methodology, triangulation, mixed methods

\section{Wstęp}

Odmienne założenia ontologiczne i epistemologiczne badań ilościowych i jakościowych sprawiają, że ich zwolennicy dość często nie darzą się sym-

${ }^{1}$ Artykuł przeglądowy przygotowany dzięki finansowemu wsparciu z grantu przyznanego autorowi przez Narodowe Centrum Nauki [nr 2012/05/D/HS6/03350]. 
patią. Podważając sens uprawiania badań ilościowych, zwolennicy orientacji jakościowej podkreślają, że w nauce „istnieją małe kłamstwa, duże kłamstwa oraz statystyka". Odpierając zarzut, ilościowcy, w równie zjadliwy sposób, zauważają, że w ramach paranauki „istnieje wróżenie z ręki, wróżenie z fusów i badania jakościowe” i dodają zjadliwie, że „w badaniach jakościowych, jakoś to będzie".

Zwolennicy podejścia ilościowego krytykowani są za praktykę kwantyfikowania danych, to jest mierzenia zjawisk, nawet jeżeli nie mają one charakteru ilościowego (zgodnie z ulubioną sentencją badaczy ilościowych, że liczy się tylko to, co się liczy. Innymi słowy, znaczenie ma tylko to, co można zmierzyć, to jest ująć za pomocą liczb, cyfr lub znaków graficznych²). Próby matematyzacji świata społecznego, zdaniem badaczy jakościowych, prowadzą do uniformizacji z natury niepowtarzalnych jednostek (badanych osób, grup społecznych i/lub instytucji), a w konsekwencji formułowania na ich temat fałszywych wniosków. „Na co dzień kontaktujemy się, rozmawiamy i kłócimy z konkretnym Markiem, Bronkiem, Ewą lub Anią, a nie średnią arytmetyczną, a tym bardziej odchyleniem standardowym, obliczanym dla konkretnej grupy osób" - przekonują zwolennicy orientacji jakościowej³

Z drugiej strony, "jakościowcy" krytykowani są za brak standaryzacji procedur badawczych (,jakoś to będzie”). Wskazana cecha, zdaniem badaczy ilościowych, sprawia, że badań jakościowych nie da się systematycznie powtarzać (replikować), a tym samym kontrolować adekwatności tworzonych na ich podstawie wniosków. "Jeżeli nawet nasze badania są obarczone błędem, to - w przeciwieństwie do "jakościowców” - jesteśmy w stanie błąd ten obliczyć i minimalizować jego wartość w badaniach replikacyjnych" - podkreślają zwolennicy orientacji ilościowej ${ }^{4}$.

\section{Metodologiczni ekstremiści}

W pewnym uproszczeniu, badaczy społecznych można rozmieścić na kontinuum, reprezentującym poziom wyrażanej aprobaty wobec określonego paradygmatu. Na przeciwległych biegunach skali znajdują się radykalni

${ }^{2}$ C.H. Coombs, R.M. Dawes, A.N. Tversky, Wprowadzenie do psychologii matematycznej, przekł. J. Grzelak, T.B. Iwiński, J. Radzicki, T. Tyszka, Warszawa 1977.

${ }^{3}$ M.L. Smith, Multiple methodology in education research, [w:] Handbook of complementary methods in education research, red. J.L. Green, G. Camilli, P.B. Elmore, Washington D.C-Mahwah, New Jersey 2006, s. 457-475; U. Flick, Projektowanie badania jakościowego, przekł. P. Tomanek, Warszawa 2010.

${ }^{4}$ B. Wojciszke, Systematyczne modyfikowane autoreplikacje: logika programu badań empirycznych w psychologii, [w:] Metodologia badań psychologicznych. Wybór tekstów, red. J.M. Brzeziński, Warszawa, 2006, s. 19-54; M. Mitchell, J. Jolley, Research design explained, Wadsworth 2012. 
zwolennicy orientacji ilościowej i jakościowej. Prowadzone przez nich badania są podporządkowywane regule niesprzeczności paradygmatycznej. Zgodnie $\mathrm{z}$ nią, jeżeli badacz organizuje badania i gromadzi dane w ramach jednego podejścia (np. ilościowego), to bezwarunkowo należy je interpretować w świetle założeń tego samego paradygmatu 5 .

Jerzy M. Brzeziński ${ }^{6}$ podkreśla:

odnoszenie hipotezy wyrażonej w języku teorii $\mathrm{T}^{1}$, należącej do paradygmatu $\mathrm{P}^{1}$, do jakichś elementów teorii $\mathrm{T}^{2}$, należącej do paradygmatu $\mathrm{P}^{2}$, nie może przynieść wartościowych poznawczo rezultatów, gdyż równocześnie używa dwóch nieprzekładalnych na siebie języków. Mówi „,cos”, ale nie bardzo wiadomo w system jakiej wiedzy to "coś” można wbudować. Nie można bowiem odwoływać się jednocześnie do języka ortodoksyjnej psychoanalizy (jeden paradygmat) oraz do języka behawioryzmu (drugi paradygmat). Oba bowiem paradygmaty reprezentują całkowicie odmienne punkty widzenia na naturę ludzkiego zachowania.

W przeciwnym wypadku badacz jest w stanie udowodnić wszystko co zechce, na przykład nie mogąc na podstawie zebranego materiału empirycznego udowodnić słuszności hipotezy katharsis (zakładającej, że oglądanie i przeżywanie aktów przemocy, np. meczu bokserskiego w TV, redukuje poziom odczuwanego napięcia, a w konsekwencji - osobniczą chęć pobicia partnera interakcji). Dziwnym trafem, po meczach piłki nożnej, podczas których jedna grupa zawodników chce pokonać drugą grupę zawodników, kibice drużyn przeciwnych nie starają się - jak zakłada hipoteza katharsis - bratać, lecz przeciwnie, zgodnie z „miejską tradycją”, starają się wyeliminować przeciwnika7, badacz może wyjaśnić uzyskane wyniki na gruncie radykalnego behawioryzmu, kognitywizmu, ewolucjonizmu, a nawet psychologii egzystencjalnej, dowodząc słuszności stawianych wcześniej tez. Postępowanie takie byłoby nadzwyczaj wygodne (skuteczność falsyfikowania stawianych hipotez - przewidywań, a zatem racji badacza, wynosiłaby $0 \%$. Innymi słowy, badacz zawsze miałby rację, choć nie zawsze mówiłby prawdę $e^{8}$, ale metodologicznie niepoprawne ${ }^{9}$

${ }^{5}$ E. Paszkiewicz, Struktura teorii psychologicznych, Warszawa 1983; J. Skarbek, Pozytywistyczna teoria wiedzy, Warszawa 1995; J.M. Brzeziński, Badania eksperymentalne w psychologii i pedagogice, Warszawa 2008.

${ }^{6}$ J.M. Brzeziński, Badania eksperymentalne, s. 15.

${ }^{7}$ R.G. Geen, D. Stonner, G.L. Shope, Agresja sprzyja agresji: materiat dowodowy przeciw hipotezie katharsis, [w:] Człowiek istota społeczna. Wybór tekstów, red. E. Aronson, Warszawa 2005, s. 377-388.

${ }^{8}$ K.R. Popper, Logika odkrycia naukowego, przekł. U. Niklas, Warszawa 2002.

${ }^{9}$ E. Paszkiewicz, Struktura teorii psychologicznych; M. Hammersley, Troubles with triangulation, [w:] Advances in mixed methods research: Theories and applications, red. M.M. Bergman, London 2008, s. 22-36. 
Wynika z tego, że dane pochodzące $\mathrm{z}$ badań eksperymentalnych nie mogą być interpretowane jakościowo - w rzędach liczb pochodzących z pomiaru nie należy poszukiwać sensu innego (tj. głębszego, humanistycznego) niż ten, jaki wynika z użytego poziomu pomiaru. Dla odmiany, dane uzyskane w swobodnym wywiadzie mogą służyć do formułowania wniosków na temat stanów wewnętrznych i zachowań jednostek, ale nie relacji przyczynowoskutkowych lub jakichkolwiek innych regularności (np. współwystępowania) dotyczących analizowanych fenomenów.

Clifford Geertz ${ }^{10}$, wybitny antropolog i zwolennik podejścia rozumiejącego w naukach społecznych, stwierdza:

wierząc, że człowiek jest zwierzęciem zawieszonym w sieciach znaczeń, które sam utkał, pojmuję kulturę jako owe sieci, których analiza nie jest zatem nauką eksperymentalną, poszukującą praw, lecz nauką interpretatywną poszukującą znaczenia ${ }^{11}$.

\section{Umiarkowani zwolennicy badań ilościowych i jakościowych w naukach społecznych}

Między wskazanymi biegunami znajdują się umiarkowani zwolennicy założeń orientacji ilościowej i jakościowej, podporządkowujący badania regule dominacji przedmiotu badań nad metodą ${ }^{12}$. Zgodnie z nią, podczas rozwiązywania tego samego problemu, na przykład analizy osobowościowych determinant poczucia szczęścia u pracowników międzynarodowych korporacji, możliwe jest łączenie ilościowych i jakościowych metod badań, o ile gromadzone w ten sposób dane empiryczne są bogatsze, a wyprowadzane na ich podstawie wnioski trafniejsze. Podejście takie nosi nazwę triangulacji metod badań ${ }^{13}$.

Umiarkowani zwolennicy paradygmatu badań ilościowych uznają, że jakościowe metody gromadzenia danych mogą pełnić funkcję pomocniczą wobec badań właściwych (tj. ilościowych). Można wyobrazić sobie sytuację, w której badacz prowadzi obserwację kontrolowaną lekarzy i pacjentów publicznejsłużby zdrowia. Badacz zastanawia się,jakieczynniki pozamedyczne mogą wpływać na dynamikę procesu zdrowienia. Zauważa, że niektórzy lekarze są ponurzy, natomiast inni często się uśmiechają, a rozmawiając, utrzymują kontakt wzrokowy $\mathrm{z}$ pacjentami. W świetle zgromadzonego materiału empirycznego stwierdza, na przykład korzystając z wybranego

\footnotetext{
${ }^{10}$ C. Geertz, Opis gesty - w stronę interpretatywnej teorii kultury, [w:] Badanie kultury. Elementy teorii antropologicznej, red. M. Kempny, E. Nowicka, Kraków 2003, s. 35-58.

${ }^{11}$ Tamże, s. 36.

${ }^{12}$ J.W. Creswell, Research design: Qualitative, quantitative, and mixed methods approaches, London 2014.

${ }^{13}$ U. Flick, Jakość w badaniach jakościowych, przekł. P. Tomanek, Warszawa 2011.
} 
testu statystycznego, że czas rekonwalescencji pacjentów kontaktujących się z lekarzami oschłymi jest dłuższy niż pacjentów leczonych przez serdecznych lekarzy.

Regułęogólną, odkrytą w badaniachilościowych (nomotetycznych), można zilustrować danymi jakościowymi, typowymi dla badań idiograficznych ${ }^{14}$. W tym celu ten sam lub inny badacz prowadzi swobodne wywiady z pacjentami. Pan Marian na pytanie, jak się czuje podczas wizyt u lekarza rodzinnego, odpowiada: U nas w przychodni lekarze to raczej odburkuja niz rozmawiaja z pacjentami. Ogólnie klimat nie jest przyjazny. A ile trzeba się naprosić, by dostać skierowanie na specjalistyczne badanie. Czasem aż mi sie odechciewa... Dla odmiany Pan Maciej - pacjent serdecznego lekarza - podkreśla: tak, Pani doktor jest bardzo miła, dopytuje o różne szczegóty. Ostatnio przepisała mi nowy lek, po którym poczułem się zdecydowanie lepiej... Łatwo zauważyć, że panujący w gabinecie klimat emocjonalny - zachęcający lub onieśmielający pacjentów do wyrażania próśb o przepisanie im nowoczesnych leków lub procedur medycznych jest czynnikiem, który znacząco wpływa na dynamikę procesu zdrowienia $^{15}$.

Kolejny przykład podaje, że inny badacz planuje badania ankietowe na temat preferencji muzycznych studentów poznańskich uczelni wyższych. W tym celu przygotowuje pytania, które zostaną włączone do ostatecznej wersji kwestionariusza. Autor badań ma wątpliwości: o co warto pytać? Czy utwory zespołu Led Zeppelin są obecnie równie popularne, jak w latach 70. ubiegłego wieku? Czy piękno piosenek Budki Suflera wzrusza słuchaczy tak samo głęboko, jak dekadę temu?

Przed przystąpieniem do badań właściwych, ich autor przeprowadza badanie wstępne (badanie pilotażowe), podczas którego korzysta z metod jakościowych - obserwacji i wywiadu swobodnego ${ }^{16}$. Z przeprowadzonych rozmów ze studentami wynika, że „wapna się nie słucha... jak Budka Suflera może wzruszać, skoro nie wzrusza”. Jedna osoba - Grzesiek, stały bywalec dyskotek - podkreśla, że: czas żywej muzyki to przeszłość. Obecnie na miasteczku stucha się...

${ }^{14}$ J.J. Shaughnessy, E.B. Zechmeister, J.S. Zechmeister, Metody badawcze w psychologii, przekł. M. Rucińska, Gdańsk 2007; J. Skinner, A. Edwards, B. Corbett, Research methods for sport management, London - New York 2015.

${ }^{15}$ M.J. Harris, Issues in studying the mediation of expectancy effects: A taxonomy of expectancy situations, [w:] Interpersonal expectations: Theory, research and applications, red. P.D. Blanck, New York 1993, s. 350-378; M.R. DiMatteo, Expectations in the physician-patient relationship: Implications for patient adherence to medical treatment recommendations, [w:] Interpersonal expectations: Theory, research and applications, red. P.D. Blanck, New York 1993, s. 296-315.

${ }^{16}$ G. Wieczorkowska, J. Wierzbiński, Statystyka. Od teorii do praktyki, Warszawa 2011; D.T. Kenrick, S.L. Neuberg, R.B. Cialdini, Psychologia społeczna, przekł. A. Nowak, O. Waśkiewicz, M. Trzebiatowska, M. Orski, Gdańsk 2006. 
Badacz dowiaduje się o jakie gatunki muzyczne i o jakich wykonawców warto pytać, konstruując ostateczną wersję kwestionariusza ankiety. W tym przykładzie dane jakościowe posłużyły do oceny dostępności zachowań werbalnych i niewerbalnych w repertuarze badanych osób, na które warto zwrócić szczególną uwagę podczas badań właściwych, na przykład rejestrując ich częstość w trakcie obserwacji kontrolowanej lub eksperymentu itp. ${ }^{17}$

Dla odmiany, umiarkowani zwolennicy paradygmatu antypozytywistycznego uznają, że w ramach badań właściwych (tj. jakościowych), funkcję pomocniczą powinny pełnić metody badań ilościowych, na przykład ankiety, eksperymenty itp. ${ }^{18} \mathrm{Z}$ sytuacją taką mamy do czynienia, kiedy badacz po odkryciu trendu (prawidłowości), wyodrębnia przypadki odstające lub skrajne, to jest wykraczające o +/- dwa odchylenia standardowe poza wartość średniej arytmetycznej, obliczonej dla określonego zjawiska $w$ badanej grupie. Następnie przypadki skrajne są szczegółowo opisywane i kontrastowane z przypadkami mieszczącymi się $\mathrm{w}$ ogólnie przyjętej normie.

Można wyobrazić sobie sytuację, w której badacz ocenia relację między temperaturą powietrza a wytrzymałością ludzi w zadaniach poznawczych i fizycznych. W tym celu codziennie o godz. 9.00 rano mierzy temperature powietrza $\mathrm{w}$ Warszawie, a następnie prosi osoby badane o możliwie szybkie wykonanie dwóch zadań: obliczenie pięciu średnio trudnych zadań z matematyki, a następnie - o pokonanie trzech tysięcy schodów Pałacu Kultury. W eksperymencie uczestniczy 120 wolontariuszy - studentów różnych kierunków studiów, w wieku od 20 do 22 roku życia. Odkryty trend obrazuje rycina 1 .

Wyraźnie widać, że wraz ze wzrostem temperatury powietrza, czas potrzebny na wykonanie zadań poznawczych i fizycznych wzrasta. Ponadto, poza odkrytym trendem, zawierającym wyniki $95 \%$ osób (por. przerywane linie powyżej i poniżej linii regresji) znajdują się dwa odstające przypadki - wyniki Karola i Bronka. Mimo sprzyjająco niskiej temperatury powietrza $\left(17^{\circ} \mathrm{C}\right)$, wyniki Karola są zaskakująco niskie (120 minut). Karol potrzebował blisko dwukrotnie więcej czasu na rozwiązanie zadań matematycznych i pokonanie kilku tysięcy schodów niż pozostali studenci. Dla odmiany, zaskakująco wysokie wyniki uzyskał Bronek, który pomimo zabójczo wysokiej temperatury powietrza $\left(33^{\circ} \mathrm{C}\right)$ błyskawicznie rozwiązywał zadania matematyczne i wspinał się po schodach Pałacu Kultury i Nauki (55 minut).

${ }^{17}$ G. Wieczorkowska, J. Wierzbiński, Statystyka; J.W. Creswell, Research design: Qualitative, quantitative.

${ }^{18}$ M.L. Smith, Multiple methodology, s. 457-475; I. Newman, Mixed methods research: Exploring the interactive continuum, Carbondale 2008; M. Hammersley, Troubles with triangulation, s. 22-36. 


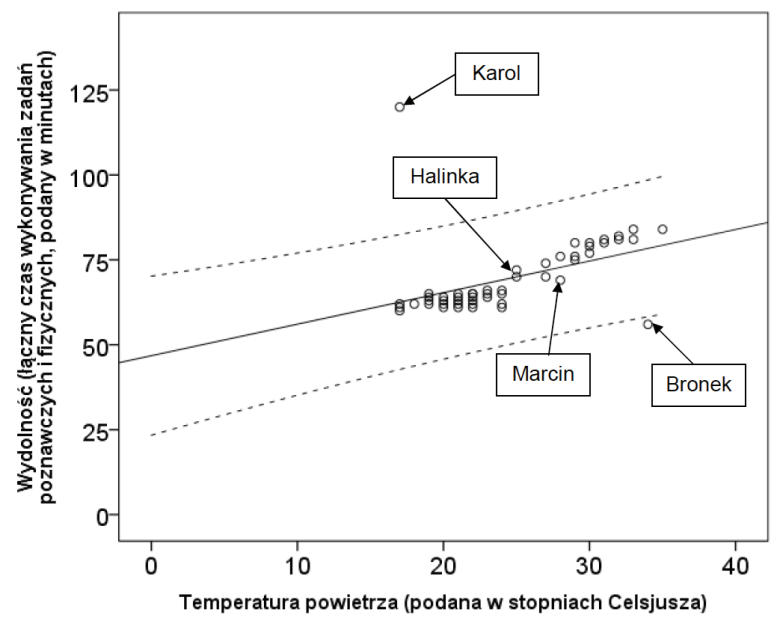

Ryc. 1. Relacja między temperaturą powietrza a wydolnością poznawczą i fizyczną uczestników badania (wyniki hipotetyczne)

Czy wyniki Karola i Bronka są zastanawiające? Zdecydowanie tak. W związku z tym, drążąc temat, ten sam badacz postanawia przeanalizować zarejestrowane różnice. W tym celu kontaktuje się z mężczyznami i korzystając z wybranych metod badań jakościowych, gromadzi potrzebny materiał empiryczny, na przykład prowadzi swobodną obserwację i wywiady, pytając badane osoby o ich samopoczucie w upalne i chłodne dni, stosunek do wysiłku poznawczego i fizycznego, podejmowane aktywności fizyczne, dietę, stan zdrowia itp.

Zebrane $\mathrm{w}$ ten sposób informacje badacz może skonfrontować $\mathrm{z}$ danymi uzyskanymi od osób (Halinka i Marcin), których wyniki nie wykraczały poza odkryty trend ogólny. Dzięki temu autor badań jest w stanie określić warunki, na przykład stany wewnętrzne osób, odpowiedzialne (lub współodpowiedzialne) za zaobserwowane anomalie. $W$ celu sprawdzenia trafności przyjętych założeń, badacz może ponownie przeprowadzić obserwację terenową lub swobodnie porozmawiać z badanymi osobami (przypadkami skrajnymi vs przeciętnymi).

Podsumowując, badacze społeczni mogą korzystać z procedur triangulowania, to jest łączenia, w różnych proporcjach, metod badań ilościowych i jakościowych ${ }^{19}$. W podanym na początku artykułu przykładzie (analiza relacji między atmosferą gabinetu lekarskiego a szybkością zdrowienia klien-

${ }^{19}$ I. Newman, Mixed methods research; M.M. Bergman, Advances in mixed methods research: Theories and applications, London 2008, s. 22-36; J.W. Creswell, V.L. Plano Clark, Designing and 
tów publicznej służby zdrowia), w I etapie badania, ich autor gromadził dane empiryczne korzystając z metody obserwacji standaryzowanej (podejście nomotetyczne). Następnie, po odkryciu ogólnej prawidłowości („,pacjenci lekarzy życzliwych zdrowieją istotnie szybciej niż pacjenci lekarzy oschłych"), w etapie II, badacz ilustrował ją wypowiedziami pacjentów, u których proces zdrowienia był bardziej (Pan Maciej) vs mniej (Pan Marian) dynamiczny (podejście idiograficzne).

W przykładzie drugim (badania ankietowe na temat preferencji muzycznych studentów poznańskich uczelni wyższych), podczas przygotowywania kwestionariusza, autor w etapie I badania korzystał z wywiadu pogłębionego (podejście idiograficzne). Następnie, po ustaleniu dostępności różnego typu odpowiedzi i włączeniu ich do ostatecznej wersji kwestionariusza, w II etapie gromadził dane za pomocą wywiadu ustrukturyzowanego (podejście nomotetyczne).

$\mathrm{Na}$ koniec, oceniając związek między temperaturą powietrza a wydolnością poznawczą i fizyczną studentów, w I etapie badacz korzystał z procedur eksperymentalnych (podejście nomotetyczne). Następnie, po wyodrębnieniu trendu oraz przypadków odstających (Karol i Bronek), w II etapie eksperymentator gromadził dodatkowe informacje posługując się wywiadem pogłębionym i swobodną obserwacją uczestniczącą (podejście idiograficzne).

Spór między zwolennikami paradygmatu ilościowego i jakościowego wydaje się niepotrzebny, a nawet bezsensowny. Obie perspektywy - nomotetyczna i idiograficzna - są jak dwie strony tego samego medalu. Ich łączenie (triangulowanie) pozwala docierać do bogatszych danych, dzięki którym badane zjawiska, na przykład relacja między poziomem optymizmu a liczbą posiadanych przyjaciół (por. ryc. 2), mogą być analizowane z punktu widzenia jednostek, na przykład konkretnego Karola (awers medalu - perspektywa idiograficzna), oraz ogólnych prawidłowości, rządzących zachowaniami badanej grupy osób (rewers medalu - perspektywa nomotetyczna).

Warto podkreślić - udana interpretacja radosnych doświadczeń Karola jest możliwa, o ile są one analizowane w szerszej perspektywie, to jest szczęścia pozostałych członków grupy, istotnie powiązanego z liczbą posiadanych przez te osoby przyjaciół. Z drugiej strony, ogólna prawidłowość (trend, zgodnie z którym wraz ze wzrostem liczby przyjaciół wzrasta poziom odczuwanego zadowolenia z życia), odkrywana na podstawie danych grupowych, nabiera znaczenia w świetle jednostkowego nieszczęścia osób samotnych lub szczęścia ludzi, otaczających się liczną grupą przyjaciół.

conducting mixed methods research, Thousand Oaks 2011; J.W. Creswell, Research design: Qualitative, quantitative. 


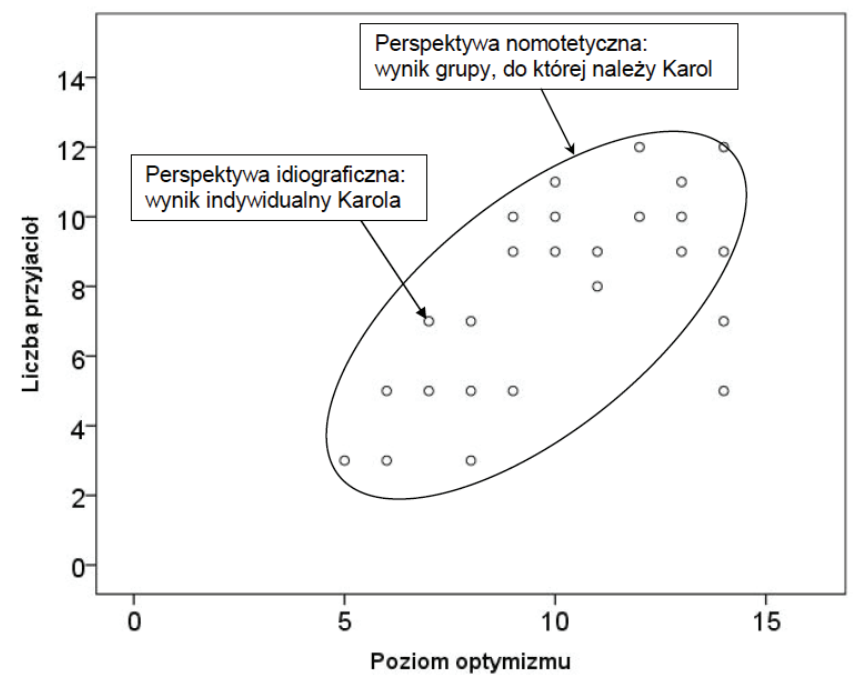

Ryc. 2. Złożenie dwóch perspektyw badań - nomotetycznej i idiograficznej $-\mathrm{w}$ analizie danych empirycznych

\section{Dwie perspektywy, ten sam przedmiot badania}

Oprócz procedury triangulowania metod badań, naukowcy zestawiają i porównują dane pochodzące $z$ różnych źródeł. Wskazane podejście nosi nazwę triangulacji źródeł danych ${ }^{20}$. Wyobraź sobie, że w prowadzonych badaniach ich autor sprawdza, jakie czynniki środowiska szkolnego chronią, a jakie wpływają patogennie na proces rozwoju poznawczo-społecznego dzieci euromigrantów. Potrzebne dane gromadzisz, rozmawiając z dziećmi. Od Staszka - ucznia klasy VI - dowiadujesz się, że przyczyną jego kłopotów w nauce są „złośliwi nauczyciele”, którzy "tak jakoś się uwzięli”.

Czy na podstawie wypowiedzi jednego dziecka można sformułować wniosek, że za problemy w nauce dzieci euromigrantów odpowiadają ",twardogłowi” nauczyciele. Zdecydowanie nie. Prawdy jednostronne to często „półprawdy", które warto konfrontować z opiniami innych osób. Rekonstruując sytuację dzieci euromigrantów, warto zatem uwzględnić punkt widzenia nauczycieli, rówieśników, rodziców itp., traktując je jako alternatywne źródła danych ${ }^{21}$.

Kierując się tą zasadą, badacz rozmawia o chłopcu z jego wychowawcą. „Staszek nawet świętego mógłby wściec" - podkreśla nauczyciel i opowia-

${ }^{20}$ U. Flick, Jakość w badaniach jakościowych.

${ }^{21}$ M. Hammersley, P. Atkinson, Metody badań terenowych, przekł. S. Dymczyk, Poznań 2000; J.W. Creswell, V.L. Plano Clark, Designing and conducting. 
da o awanturach Staszka, papierosach palonych w ubikacji i wagarach. Zachowania opozycyjno-buntownicze chłopca sprawiają, że nie jest on lubiany przez nauczycieli i część rówieśników oraz wzywany bywa natychmiast do odpowiedzi, kiedy tylko pojawia się na zajęciach.

Jednocześnie badacz obserwuje Staszka, rejestrując zachowania chłopca związane z agresją i autoagresją oraz reakcje jego otoczenia związane z aprobatą/dezaprobatą vs obojętnością uczniów i nauczycieli, wyrażaną względem niego. Rzeczywiście, chłopiec nie jest zbyt miły dla ludzi. Demonstracyjnie obraża nauczycieli i rówieśników, zachowuje się wobec nich napastliwie. W skrajnych przypadkach Staszek dokonuje samookaleczeń. Badacz zauważa również natychmiastowe reakcje otoczenia na jego zachowania - nauczyciele proszą, ganią, krzyczą na chłopca, starając się zmienić jego postępowanie. Zarazem, kiedy Staszek zachowuje się zgodnie ze szkolnymi normami, wówczas jest ignorowany.

Obraz Staszka - dziecka euromigrantów - rekonstruowany na podstawie danych z różnych źródeł (tj. wypowiedzi dziecka i nauczycieli oraz obserwacji kontrolowanej) jest pełniejszy, a przez to trafniejszy, aniżeli obraz wcześniejszy - rekonstruowany wyłącznie na podstawie opinii wyrażanych przez Staszka. Jednocześnie, zestawianie alternatywnych źródeł danych nie wyklucza możliwości gromadzenia ich za pomocą różnych, ilościowych i jakościowych, metod badań podczas rozwiązywania tego samego problemu (lub testowania tych samych hipotez).

\section{Podsumowanie}

Na koniec, praktyczne znaczenie procedur triangulacji metod i źródeł danych w badaniach społecznych warto zilustrować metaforą rzutu prostokątnego tej samej figury geometrycznej. Patrząc na nią od frontu widać prostokąt (por. ryc. 3a), natomiast od góry - okrąg (por. ryc. 3b).
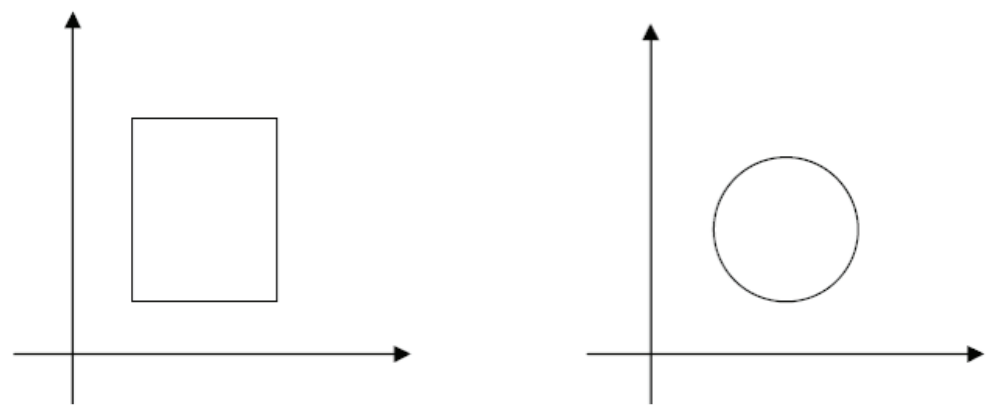

Ryc. 3a i 3b. Rzut prostokątny figury geometrycznej - widok od frontu (3a) oraz z góry (3b) 
Przedstawiona figura nie jest jednak ani prostokątem, ani okręgiem. Z jaką zatem figurą geometryczną mamy rzeczywiście do czynienia? Rzecz jasna z walcem (por. ryc. 3c), o czym można się przekonać łącząc (tj. triangulując) obraz prostokąta i okręgu. Tylko wówczas można sformułować trafny wniosek na temat kształtu oglądanej figury geometrycznej (bryły).

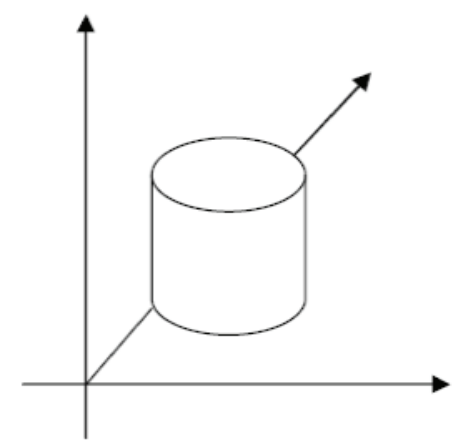

Ryc. 3c. Obraz figury geometrycznej po złożeniu (triangulacji) perspektywy 3a i 3b

Jeżeli przyjmiemy, że prostokąt symbolizuje nomotetyczną, a okrąg idiograficzną perspektywę badań wraz z typowymi dla nich procedurami zbierania danych, można uznać, że analizowanie jakichkolwiek zjawisk, na przykład stygmatyzacji osób niepełnosprawnych w ramach wyłącznie badań ilościowych vs jakościowych, skazuje badaczy na formułowanie jednostronnych, często tendencyjnych (nietrafnych) wniosków.

Rekonstruowany obraz zjawisk jest pełniejszy, a dzięki temu bardziej wiarygodny, o ile badacz stosuje strategie triangulowania danych, gromadzonych za pomocą różnych - ilościowych i jakościowych - metod i pochodzących z różnych źródeł osobowych (np. wypowiedzi konkretnego Ryśka, ojca konkretnego Wojtka - ucznia klasy III LO) i pozaosobowych (np. dokumentacji dotyczącej funkcjonowania szpitala rejonowego w Kluczborku lub Sądu Rejonowego w Skawinie).

\section{BIBLIOGRAFIA}

Bergman M.M., Advances in mixed methods research: Theories and applications, Sage Publications, London 2008.

Brzeziński J.M., Badania eksperymentalne w psychologii i pedagogice, Wydawnictwo Naukowe Scholar, Warszawa 2008.

Coombs C.H., Dawes R.M., Tversky A.N., Wprowadzenie do psychologii matematycznej, przekł. J. Grzelak, T.B. Iwiński, J. Radzicki, T. Tyszka, Państwowe Wydawnictwo Naukowe, Warszawa 1977. 
Creswell J.W., Plano Clark V.L., Designing and conducting mixed methods research, 2nd Edition, Sage Publications, Thousand Oaks 2011.

Creswell J.W., Research design: Qualitative, quantitative, and mixed methods approaches, Sage Publications, London 2014.

DiMatteo M.R., Expectations in the physician-patient relationship: Implications for patient adherence to medical treatment recommendations, [w:] Interpersonal expectations: Theory, research and applications, red. P.D. Blanck, Cambridge University Press, New York 1993.

Flick U., Projektowanie badania jakościowego, przekł. P. Tomanek, Wydawnictwo Naukowe PWN, Warszawa 2010.

Flick U., Jakość w badaniach jakościowych, przekł. P. Tomanek, Wydawnictwo Naukowe PWN, Warszawa 2011.

Geen R.G., Stonner D., Shope G.L., Agresja sprzyja agresji: materiat dowodowy przeciw hipotezie katharsis, [w:] Człowiek istota społeczna. Wybór tekstów, red. E. Aronson, Wydawnictwo Naukowe PWN, Warszawa 2005.

Geertz C., Opis gesty - w strone interpretatywnej teorii kultury, [w:] Badanie kultury. Elementy teorii antropologicznej, red. M. Kempny, E. Nowicka, Wydawnictwo UJ, Kraków 2003.

Hammersley M., Troubles with triangulation, [w:] Advances in mixed methods research: Theories and applications, red. M.M. Bergman, Sage Publications, London 2008.

Hammersley M., Atkinson P., Metody badań terenowych, przekł. S. Dymczyk, Zysk i S-ka Wydawnictwo, Poznań 2000.

Harris M.J., Issues in studying the mediation of expectancy effects: A taxonomy of expectancy situations, [w:] Interpersonal expectations: Theory, research and applications, red. P.D. Blanck, Cambridge University Press, New York 1993.

Kenrick D.T., Neuberg S.L., Cialdini R.B., Psychologia społeczna, przekł. A. Nowak, O. Waśkiewicz, M. Trzebiatowska, M. Orski, Gdańskie Wydawnictwo Psychologiczne, Gdańsk 2006.

Mitchell M., Jolley J., Research design explained, 8th Edition, Cengage Learning, Wadsworth 2012.

Newman I., Mixed methods research: Exploring the interactive continuum, Southern Illinois University Press, Carbondale 2008.

Paszkiewicz E., Struktura teorii psychologicznych, Państwowe Wydawnictwo Naukowe, Warszawa 1983.

Popper K.R., Logika odkrycia naukowego, przekł. U. Niklas, Fundacja Aletheia, Warszawa 2002.

Shaughnessy J.J., Zechmeister E.B., Zechmeister J.S., Metody badawcze w psychologii, przekł. M. Rucińska, Gdańskie Wydawnictwo Psychologiczne, Gdańsk 2007.

Skarbek J., Pozytywistyczna teoria wiedzy, Wydawnictwo IHN PAN, Warszawa 1995.

Skinner J., Edwards A., Corbett B., Research methods for sport management, Routledge, Taylor \& Francis Group, London - New York 2015.

Smith M.L., Multiple methodology in education research, [w:] Handbook of complementary methods in education research, red. J.L. Green, G. Camilli, P.B. Elmore, AERA-LEA, Washington D.C-Mahwah, New Jersey 2006.

Wieczorkowska G., Wierzbiński J., Statystyka. Od teorii do praktyki, Wydawnictwo Naukowe Scholar, Warszawa 2011.

Wojciszke B., Systematyczne modyfikowane autoreplikacje: logika programu badań empirycznych w psychologii, [w:] Metodologia badań psychologicznych. Wybór tekstów, red. J.M. Brzeziński, Wydawnictwo Naukowe PWN, Warszawa, 2006. 